\section{MACULAR BURNS AS A RESULT OF EXPOSURE TO GREEN LASER POINTER OF III B CLASS}

Ayan Mammadkhanova, MD

Aziz Mehtiyev, MD

Tural Galbinur, MD, PhD

(Corresponding Author)

Department of Ophthalmology, Azerbaijan Medical

University; Baku, Azerbaijan

Department of Ophthalmology, National Prime Hospital, Azerbaijan

\begin{abstract}
:
We present a clinical case of macular burn as a result of the effect of laser pointer observed in our 14-year-old patient. The laser pointer was a class III B laser according to the classification of laser power (based on the wavelength and output power of the laser). The patient focused the laser beam on his eyes for a few seconds and then noticed a black spot on both eyes. Examinations revealed decreased visual acuity in both eyes, and spectral-domain optical coherent tomography (SD-OCT) and fluorescent angiography (FAQ) revealed defects in the outer lamellar layers of the retina. Topical corticosteroids and non-steroidal anti-inflammatory drops were used for treatment. Re-examination after 3 months showed some clinical improvement, but there were persistent effects.
\end{abstract}

Keywords: Macular burn, laser pointer, laser injury, laser safety

\begin{tabular}{|l|l|}
\hline \multicolumn{2}{|c|}{ Access this article online } \\
\hline Quick Response Code: & Website: \\
https://ophthalmolcases.com/index.php/ \\
hat
\end{tabular}

In recent years, the number of people seeking help from ophthalmologists for burns caused by laser pointers has been steadily increasing, especially among children and adolescents 1,2. This situation emphasizes the importance of careful use of laser devices because improper use of these devices can endanger vision. According to the Food and Drug Administration (FDA), the power output of laser pointers and laser toys should be limited to 5 milliwatts $(\mathrm{mW})$ 3. However, as laser technology evolved, laser devices became more powerful, portable (e.g., pointers and toys), widely available and affordable.

\section{Case Reports}

The 14-year-old boy was referred to our clinic by his parents complains of a black spot in his eyes for one week. The anamnesis showed that the patient aimed the green laser beam at both eyes for a few seconds. The laser has a wavelength of 632 $\mathrm{nm}$ and an output power of $50 \mathrm{~mW}$ and is classified as class III b by the FDA. The examination did not reveal any pathology of the mental status, ophthalmology or family history of the adolescent. Best corrected visual acuity (BCVA): right eye (OD) 20/63, left eye (OS) -20/40.Refraction: OD sphere (sph) -0.25 cylinders (cyl) -0.5 axis (ax) 117, OS sph 0.0 cyl-0.5 ax 39. Anterior segment examination and intraocular pressure were within normal limits in the OU. Both anterior segments were normal, there were no cells in the vitreous, and the intraocular pressure was normal in both eyes. Delated fundus examination revealed a yellow-orange retinal lesion and pigmentary changes at the fovea in both eyes [Figure. 1, 2]

Figure. 1. Right eye-color fundus photograph at yellow-orange retinal lesion and pigmentary changes in the macula

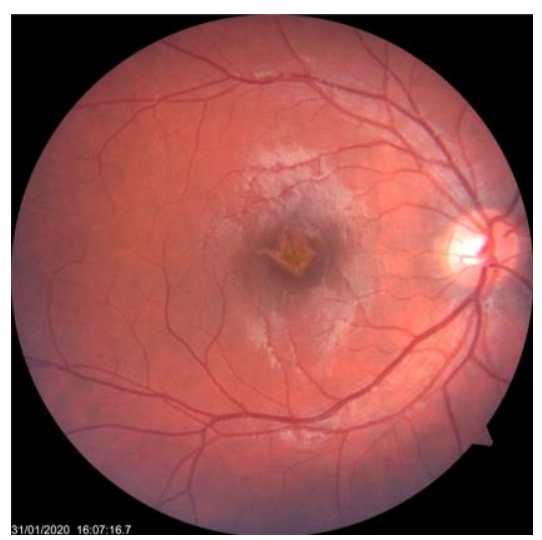




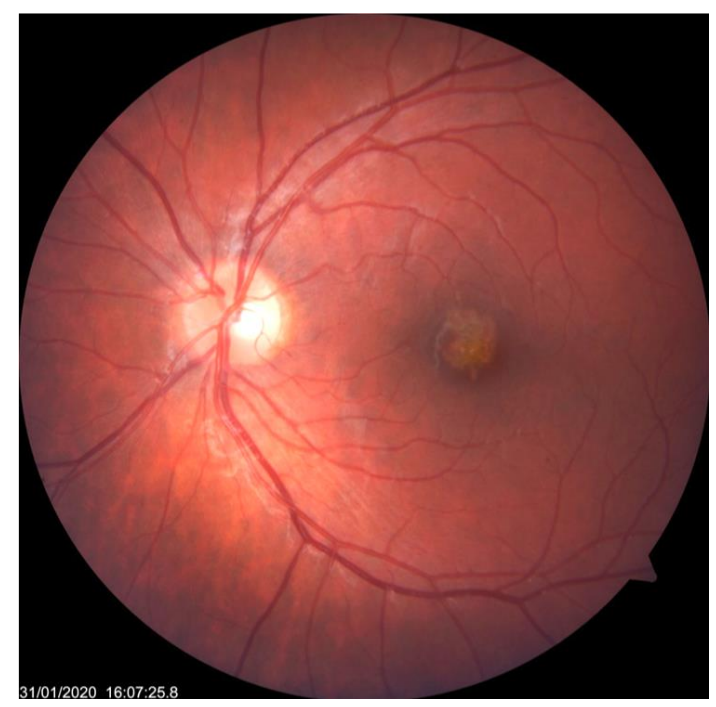

Figure.2. Left eye -color fundus photograph at presentation with pigmentary changes in the macula.

Spectral-domain optical coherent tomography (SD-OCT) revealed defects in the outer lamellar layer of the retina (ellipsoid zone and retinal pigment epithelium) [Figure. 3,4].

Figure 3. Right eye. OCT image obtained at initial presentation, showing focal disruption of the inner segment/outer segment junction and inner aspect of the retinal pigment epithelium.

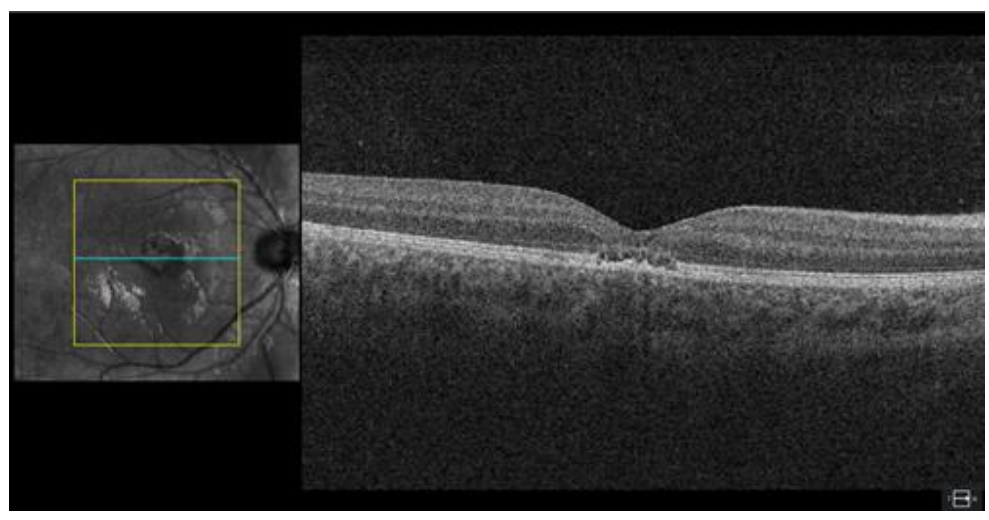

Figure 4. Left eye. OCT image obtained at initial presentation, showing focal disruption ofthe inner segment/outer segment junction and inner aspect of the retinal pigment epithelium.

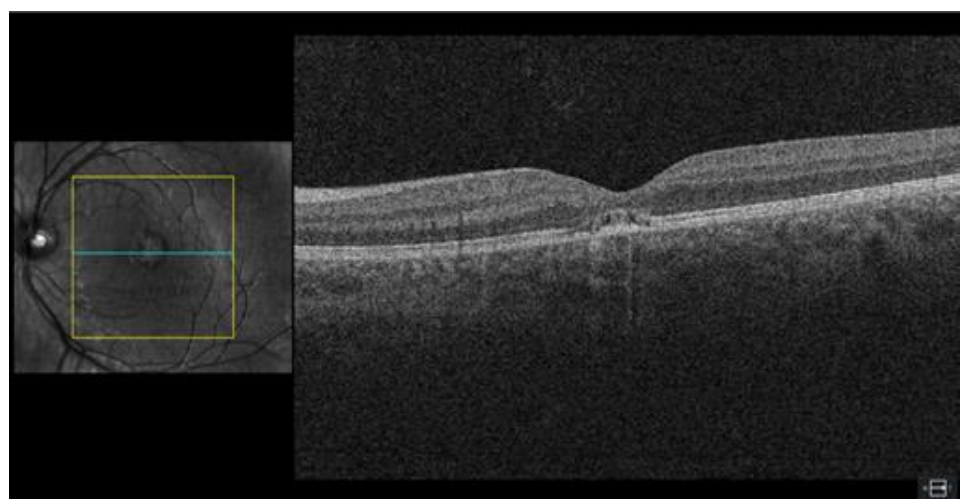

Fluorescein angiography (FA) OU -revealed "window" defect in the macular area [Figure .5,6].

Figure. 5. Right eye. Fluorescent angiography.

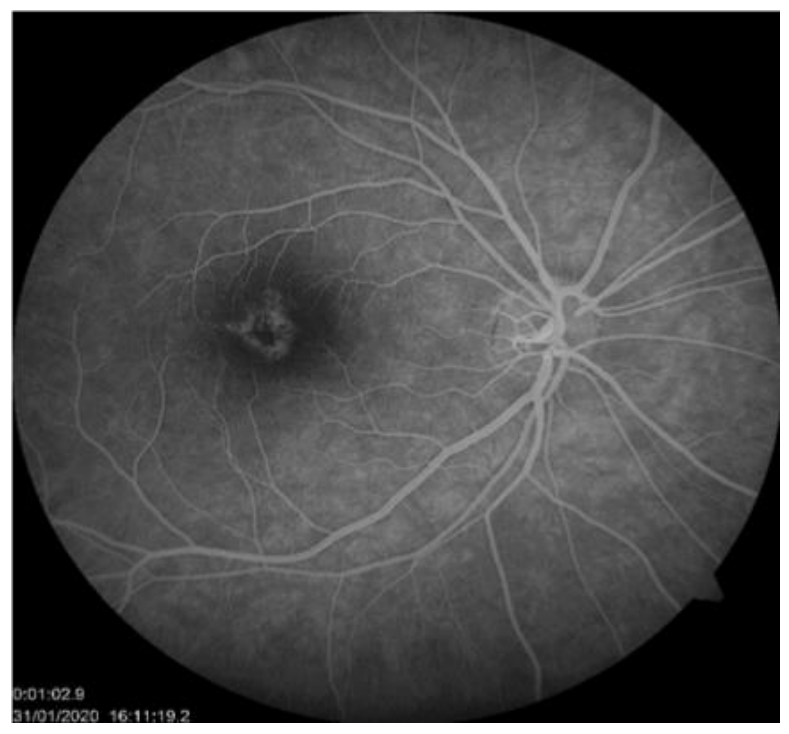

Figure. 6. Left eye. Fluorescent angiography.

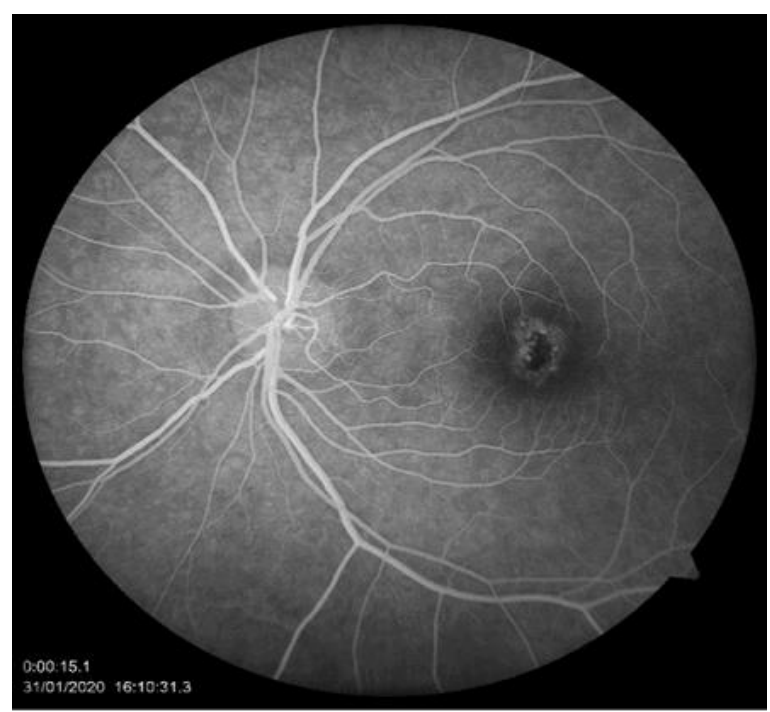

The patient was diagnosed with macular burns as a result of exposure to a green laser pointer (bilateral laser pointer induced maculopathy).The patient received prednisolone acetate 1\% (Pred Forte) under the control of intraocular pressure for 1 month and topical nonsteroidalanti-inflammatory drug Nepafenac $0.1 \%$ (Nevanac) for 3months. Follow-up ranged between 3 and 6 months. Over time, improvement in visual acuity was noted to be 6/9.5 in the right eye and 6/7.5 in the left eye. On re-examination 3 months after treatment, the patient reported symptomatic improvement, and BCVA improved to OD 6/9,5 and OS 6/7,5. In repeated OCT images, the structural defects of both macula were not significantly reduced [Figure. 7,8]. 


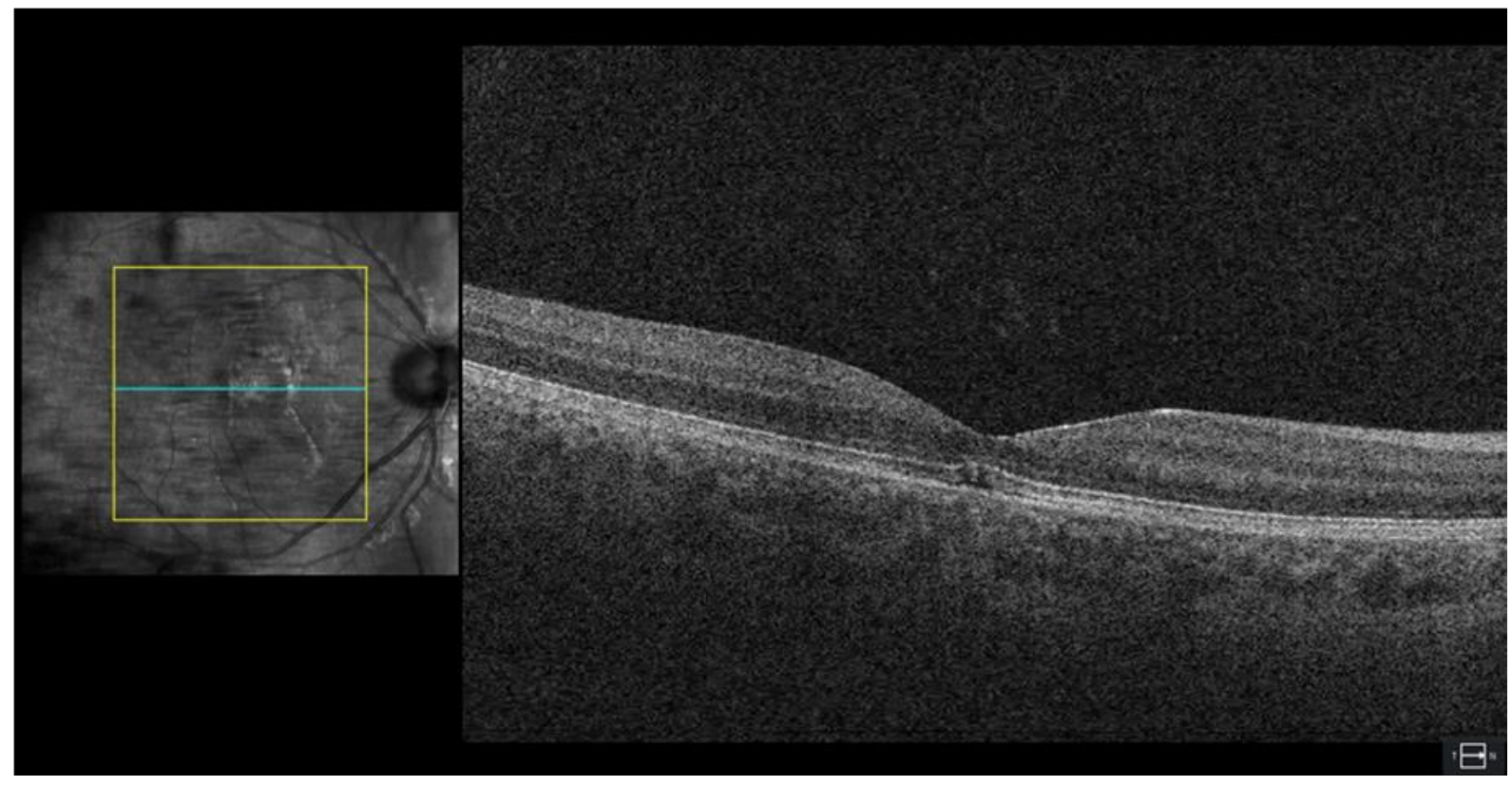

Figure 7. Right eye. SD-OCT image obtained 3 months after treatment.

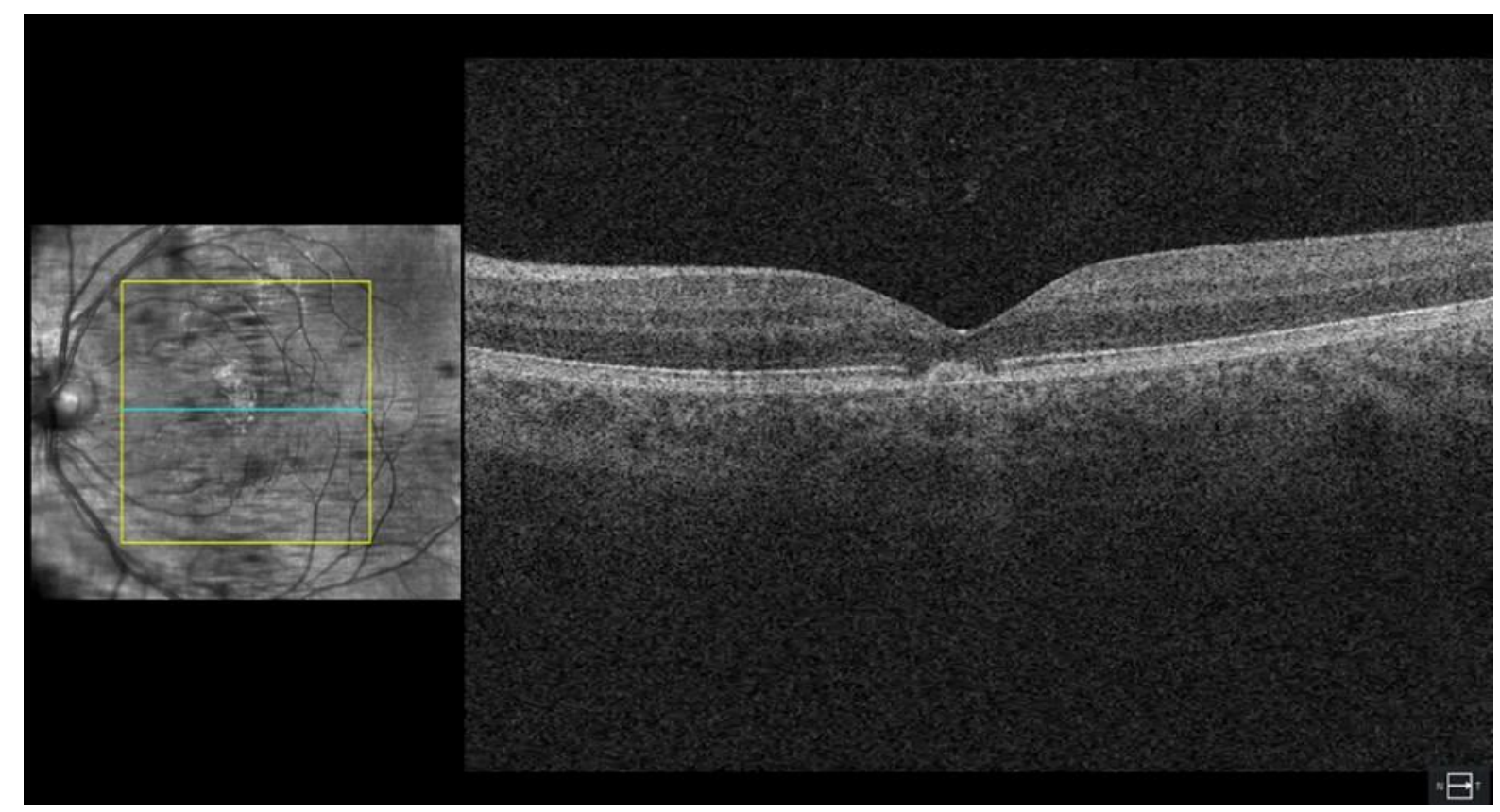

Figure. $\boldsymbol{X}$ Left eye. SD-OCT image obtained 3 months after treatment $\phi$ 


\section{Discussion}

Laser pointers are widely available. Most injuries occur due to a lack of awareness of the danger4. The main target organ is the retina, as visible and near-infrared rays are concentrated in the retina. Normally, melanin in the cells of the retinal pigment epithelium (RPE) absorbs light, and these cells also absorb light when exposed to a laser. Therefore, the retinal pigment epithelium is thought to be the most damaged area 5; however, sensitive photoreceptors close to the RPE are also at risk. Light can cause thermal, photomechanical and photochemical damage to the retina. Injuries caused by laser pointers are primarily photothermal. The energy absorbed by the tissue causes the local tissues to heat up, which can lead to protein denaturation, inflammation, and cell death 6.

In addition, the nature and severity of the injury is determined by a number of factors, including those related to the laser and the eye. These factors include the duration and amount of energy delivered, the wavelength, the duration of exposure, the location of the injury, the refraction of the person, the size of the pupil, and even the age factor 7.According to the US Food and Drug Administration (FDA), laser power is classified according to wavelength and output power (1) (table 1).

Table 1.

\begin{tabular}{|l|l|l|}
\hline $\begin{array}{l}\text { Class } \\
\text { FDA }\end{array}$ & \multicolumn{1}{|c|}{ Output power } & \multicolumn{1}{c|}{ Laser Product Hazard } \\
\hline I & Low & $\begin{array}{l}\text { Considered non-hazardous. Hazard increases if viewed withoptical aids, } \\
\text { including magnifiers, binoculars, or telescopes. }\end{array}$ \\
\hline $\begin{array}{l}\text { II a, } \\
\text { II }\end{array}$ & Less than $1 \mathrm{~mW}$ & $\begin{array}{l}\text { Hazard increases when viewed directly for long periods oftime. } \\
\text { Hazard increases if viewed with optical aids. }\end{array}$ \\
\hline III a & $\begin{array}{l}\text { Between } 1 \text { and } \\
\text { mW }\end{array}$ & $\begin{array}{l}\text { Depending on power and beam area, can be momentarily hazardous when } \\
\text { directly viewed or when staring directly at } \\
\text { the beam with an unaided eye. Risk of injury increaseswhen } \\
\text { viewed with optical aids. }\end{array}$ \\
\hline III b & $\begin{array}{l}\text { Between } 5 \text { and } \\
500 \mathrm{~mW}\end{array}$ & $\begin{array}{l}\text { Immediate skin hazard from direct beam and immediate eyehazard when } \\
\text { viewed directly. }\end{array}$ \\
\hline IV & More than $500 \mathrm{~mW}$ & $\begin{array}{l}\text { Immediate skin hazard and eye hazard from exposure to either the direct or } \\
\text { reflected beam; may also present a fire } \\
\text { hazard. }\end{array}$ \\
\hline
\end{tabular}

In accordance with FDA regulations, the use of laser pointers up to class IIIa is permitted 1,8. However, theliteraturereveals that, it is also possible to find retinal damage caused by a class III a laser pointer 9 . This, in turn, indicates that the proposed classification is not perfect.Our patient was injured by exposure to the light of a class IIIb laser pointer, which is considered dangerous, as mentioned above. Unfortunately, according to safety regulations, the pointer did not have an indication of the class to which it belonged,andit did not have a "Dangerous" label.The clinical course of retinal laser injuries is characterized by sudden vision loss and treatment options are limited 6.Laser pointers can cause permanent retinal damage and vision impairment. Because the number of complications that laser pointers can cause is likely to increase in the near future, this emphasizes the urgency of the issue. The general public should be more aware of the devices, especially for children and adolescents.

\section{Data availability statement}

The data that support the findings of this study are available from the corresponding author upon reasonable request.

Funding

None.

Study association

This study is not associated with any thesis or dissertation work

\section{Conflict of interests}

The authors declare that there is no conflict of interests. 


\section{References}

1. Performance standards for light-emitting products. U.S. Food and Drug Administration Code of Federal Regulations, Title 21, Chapter I, Subchapter J, Part 1040. Washington, DC: U.S. Government Publishing Office Bookstore. 2016. http://www.ecfr.gov/ cgibin/text-idx?SID=c656f500beebfa4cf6a442a1f8f13677\&

$\mathrm{mc}=$ true\&node $=\mathrm{pt} 21 \cdot 8 \cdot 1040 \& \mathrm{rgn}=\operatorname{div} 5 . \quad$ Accessed 05/06/2018

2. Lee GD, Baumal CR, Lally D, Pitcher JD, Vander J, Duker JS. Retinal Injury after inadvertent handheld laser exposure. Retin, J Retin Vitr Dis 2014;34:2388-96.

3. Food and Drug Administration, 2010 MedicalDevices/Safety/AlertsandNotices/ucm237129.h tm, 2010.

4. Linton E, Walkden A, Steeples LP, Bhargava A, Williams C. et al. Retinal burns from laser pointers: a risk in children with behavioural problems. Eye 2019; 33:492-504. Published online: 13 December 2018 doi: 10.1038/s41433-018-0276-z. Epub 2018 Dec 13

5. Hunter JJ, Morgan JI, Merigan WH, Sliney DH, Sparrow JR, Williams DR. The susceptibility of the retina to photochemical damage from visible light. Prog Retin Eye Res. 2012;31:28-42. doi: 10.1016/j.preteyeres.2011.11.001. Epub 2011 Nov 10.

6. Barkana Y, Belkin M Laser eye injuries. Surv Ophthalmol 2000; 44(6):459-478. DOI: 10.1016/s00396257(00)00112-0

7. U.S. Food and Drug Administration Important information for laser pointer manufacturers. 2015; https://www.fda.gov/radiation-emitting-

products/laser-products- and-instruments/importantinformation-laser-pointer-manufacturers

8. Farajpour R, Fallahi B, Farajpour S, Bagheri M. A Case of Retinal Damage Caused by Green Laser Pointer. Adv Ophthalmol Vis Syst 2015;2(5): DOI: 10.15406/aovs.2015.02.00063

9. Birtel J, Harmening WM, Krohne TU, Holz FG, Issa PC, Herrmann P. Retinal Injury Following Laser Pointer Exposure. Dtsch Arztebl Int 2017;114(49):831837. doi: 10.3238/arztebl.2017.0831.

How to cite this article: Mammadkhanova A, Mehtiyev A,Galbinur T. Macular burns as a result of exposure to green laser pointer of III B class. Ophthalmology Cases \& Hypotheses. 2020;01(01)9-13. 